Original Research Paper

\title{
A Proposed Assessment Method for Image of Regional Educational Institutions
}

\author{
Kataeva Natalya, Berezina Ekaterina and Sysolyatin Alexey \\ Vyatka State University, Russia
}

Article history

Received: 24-08-2016

Revised: 29-10-2016

Accepted: 24-03-2017

Corresponding Author:

Kataeva Natalya

Vyatka State University, Russia

Email: natalya-kataeva@yandex.ru

\section{Introduction}

Experts in marketing, public relations, sociology and psychology actively discuss the theme of image. The meaning of image as a phenomenon studied by Grunig J., Drucker P., Kotler Ph., Kono T. and other foreign scientists (Boulding, 1956), Table 1. The issues of image formation are also considered in the works of Russian authors: Tomilova M.V., Sinyaeva N.M., Havanova A.V., Sukhinov O. Yu. Techniques and methods of effective image management described by $T$. Peter and $R$. Waterman in their book "In Search of excellence".

In the Russian literature issues of company's image formation, or corporate image, become studied very recently. The reason was negative perception of this concept in the Soviet times. It was believed that image is

\begin{abstract}
Market of educational services in the current Russian economic conditions is a complex of a huge variety of educational institutions. Market of educational services is already experiencing a significant influence of the demographic situation in Russia. This means that higher school students. Increased competition in the educational market forces universities to find new methods of non-price competition in attraction of Comercialization of education places universities in a single plane with commercial companies who study a positive perception of the image and reputation as a competitive advantage, which is quite acceptable for use in strategic and current activities of higher education institutions to ensure the coducational services and educational institution in whole. Nevertheless, due to lack of evidence-based proposals in this area there is a need for scientific research in terms of justification of competitiveness of thedological aspects of image use as a factor in the practically there are different methods and ways of evaluating the company's image. The article provides a comparative assessment of the existing valuation methods of corporate image and the author's method of esting the image of higher education institutions based on the key influencing factors. The method has been tested on the Vyatka State Agricultural Academy (Russia). The results also indicate the strengths and weaknesses of the institution, highlights ways of improving and adjusts the
\end{abstract}

Keyword: Image, Education, Marketing, Competitiveness, Educational Services, Educational Institutions a manipulative technique of bourgeois policy, which is used in order to brainwash people's minds.

One of the first academics who tried to overcome this attitude was professor Feofanov O.A., who described the image as "image, which granting to the phenomenon such characteristics, which lying outside of its real essence, outside of the quality, which is disclosed in the practice of direct action". He saw the image as the primary way of psychological influence of advertiser to the consumer (Feofanov, 2000).

Vikhansky (2016) defines image as a "sustainable and widespreaded understanding of characteristics, qualities and specific features of the phenomenon". Korolko (2016) determines the image as "a mental picture about a person, product or institution, specifically emerging in public mind with the help of publicity, advertising or propaganda". 
Table 1. Conceptual approaches to image definition (Grunig J.)

\author{
Approach \\ Artistic (Grunig J.) \\ Psychological (supporters \\ -Anderson N., \\ Denis M., Horowitz M.) \\ Impressive (Goffman E.) \\ Schematic (Boulding K.)
}

\section{Definition}

Image defined as a signal generated by the device and sent directly to recipients. Image as main component of thinking, i.e., recipients create images of their own observations of reality, or of the symbols given by other people.

Image as an impression rendered by the individual or organization to anyone. Schemes are compounds, some amount of knowledge about the object, they implies a validity of information, but are not certainly those, what means according to Boulding "Knowledge has an implication of validity, of truth. What I am talking about is what I believe to be true; my subjective knowledge".
According to Russian political scientist Kosolapov N.A. image is "an artificially created in the eyes of the public image that has nothing to do with the true nature." From the point of view of Gorchakova R.R. "imageis an image that created and developed by organization, it must conform to the values, norms and requirements of the organization" (Echein, 2015).

Image is deliberately created or spontaneously raised form of the object's reflection in the minds of people. The object or the image carrier can be a person, group of people, organization and so on (Semenov and Maslova, 2009).

Image is specifically projected in the interests of the company, based on the features of its activity, internal rules, properties, advantages, qualities and performances, it is purposefully embedded into consciousness (or subconscious) of the target audience, it corresponds to the expectations and helps to distinguish the company from other similar (Lukieva, 2009).

Image is the emotionally charged stereotype formed in the mass consciousness of someone. Formation of image occurs spontaneously, but more often it is the result of special work; image reflects social expectations of the group (Arzhanova, 2015).

Ozhegov (1949) determines the image as a "form, shape; live visual representation of someone or something; generalized artistic reflection of reality in the form of a particular individual phenomenon".

The image is manipulative, attractive, easily interpreted mental form, affecting the emotional sphere of person and his subconscious and through them - the explanatory mechanisms of consciousness and behavior and human choice (Bogdanov and Zazykin, 2004).

From the above definitions can conclude the following: Determining the image all the authors agrees on the fact that there are two communicating parties: One is a source of information; the other is its recipient. There is no image out of recipients; image is fixed in symbol or message information about real objects; image, being a certain kind of message, is transmitted in process of company's communication with its "audience"; image is not necessarily true reflection of object's characteristics, but it is perceived as such; image can be raised spontaneously or purposefully created; image is able to influence and determine actions and decisions of subjects against image object.

Image of company (corporate image) is total public perception of company or firm by many people. Impressions about company are formed on the basis of: Personal contact with the company; on the basis of rumors circulating in a community; messages from mass media.

Tomilova (2016) studies corporate image as a system of impressions (images) and assessments about organization in minds of people.

However, the issue of corporate image in the context of higher education studied not deep enough.

The first publications on the corporate image of the educational institutions have appeared in Russia in the mid-1990s, when here started development of the market economy, including in the field of educational services. Experts point out that the growth of private universities has led to increased competition in the market of higher education and became a background for the formation of "the university's image." However, only in the last decade started to pay a lot of attention to the development of various aspects in image formation, so we can repeat once again that the theme of corporate image of educational institutions is at its early stage of study still.

A large number of researchers give their definition of the university's image concept. Generalization of different authors' approaches to the definition of "university's image" and their analysis suggests the following conclusions: The university's image is studied by the authors from the position of object's reflection: An overview of the object, its collective image, appearance; the university's image is seen as instrument of cognition (holistic perception (understanding and evaluation)), opinion (rational and emotional) and as a kind of social control (for the emergence of attraction to the university, to achieve the strategic objectives and tasks of organization) (Ananchenkova, 2009).

According to conclusions we suggest the author's definition of the university's image, which in our opinion is more comprehensive and uniting different approaches.

The image of higher education institution is a mental image, an idea, a set of emotions, stereotypes and associations, as well as formed on their basis opinion and attitude to institution, formed spontaneously or 
purposefully by the organization and transmitted to external and internal environment. It is affecting the consciousness and subconscious of various community groups representatives as a result of either direct contact with university, or on the basis of information received from other sources.

Image-impression gives additional value to institution that contributes to its emotional and attentive perception by the consumer. University management should identify the desired association (emotional value) of the target audience, seeking to create the conditions for their rise. Those values that image adds to educational institution may not have real basis, but at the same time have a certain importance for perceiving its audiences.

\section{Methodology}

There are theoretically and practically different methods and ways of evaluating the company's image. It is possible to assert that the best of them will be the one that meets more requirements on assessment and provides most objective results in terms of this image acceptance image by the majority of consumers.

The subject of research is the process of image evaluation of higher education institutions, the object of study is market of educational services.

The purpose of study is development of theoretical and methodological guidelines and practical recommendations on image evaluation of regional higher education institutions.

The methodological and theoretical basis of the study is dialectical method of cognition. The theoretical basis consist of the works of classical economists, the works of Russian and international economists concern of image formation in generally and in particular in the field of educational services, marketing research results, as well as the laws of Russian Ministry of Education and Science.

Information base of research was materials of Federal State Statistic Service and Regional branch of Kirov region, the publication in mass media and internal reports of higher education institutions of the city of Kirov.
Most significant results of the study are next: Were systematized the value of definitions and formulated author's definition of "image of higher education institution"; was developed the assessment method for image of higher education institutions from a regional perspective.

The most reliable way to find out what people from various community groups think about the organization is the sociological research. Main assessment methods for image of organization are in Table 2. They are divided into quantitative and qualitative.

\section{Multi-Criteria Model of Image Diagnostic}

Antipov and Pokryshevskaya (2010) were offered an approach to the joint proposal of indicators, which are important for analysis of image (companies, products), that can be calculated on the basis of typical survey data collected by companies interested in correcting positioning or image monitoring.

Analysis of contingency tables allows you to see the differences between consumers perception of different brands and to choose the correct statements for brand positioning. This is a table of frequencies built on the question "Please select the statement that you think fit this brand." The result is a table that shows number of references to each statement related to each brand.

A good way to represent the three key indicators associated with the image may be a bubble chart in which the axes are plotted the proportion of consonants and specificity rate and size of the bubbles reflects the importance of the statements. The graph allows you to assess whether the current positioning of the university desired, to identify competitive advantages and disadvantages of high school and the way of positioning correction.

A good way to represent the three key indicators associated to image is a bubble chart, where the axes are plotted proportion of agreed and specificity rate; size of bubbles reflects the importance of statements. The graph allows to assess whether the current positioning of the university is desired, to identify its competitive advantages and disadvantages and way of positioning correction.

Table 2: Classification of corporate image assessment methods

Qualitative methods
Super Profits Method (Goodwill)
Discounted Cash Flow (DCF) method
Brand Finance and Interbrand methods
V-RATIO method
The Black-Scholes options pricing model
Altman Z-score
Market value based on income
capitalization method
Evaluation of company's management effectiveness
from the perspective of protecting owner's interests
Statistical method for estimating the correlation of
company's value and main finance indicators

Quantitative methods

CS-Concept Style association method

Method for assessing integration of individuals in group DIAORG method (Voronin)

Corporate culture index assessment method

Expert assessment of main components of corporate image Evaluation of corporate image on the basis of positioning on spatial perceptual map

Assessment of public perception of corporate image

Evaluation of corporate image on the basis of factor analysis 


\section{Expert Review}

The technique is based on the idea that image as a tool to influence external environment, need to be zoomed in to a positive, thereby increasing the "market power" of company. Thus, the parameters that characterize the state of corporate image must comply with positive image. In this case, the corporate image evaluation is carried out by an expert survey of respective groups and company's employees. Corporate image is considered in two aspects: External (the company's image among consumers, business image, governance image, social image) and internal (image for staff).

To identify state of corporate image experts are invited to assess the compliance degree for each parameter with positive image, i.e., to set evaluation from 2 (if the state of this parameter does not correspond to the positive image) to 5 points (if the state of this parameter is fully consistent with the positive image).

Evaluation of corporate image and each component is determined as the average of:

$$
\bar{b}=\frac{1}{m * n} \sum_{i=1}^{m} \sum_{j=1}^{n} b_{i j}
$$

$\mathrm{B}_{\mathrm{ij}}=$ Degree of parameter compliance with positive image, gaven by j-th expert

$\mathrm{n} \quad=$ Quantity of experts

$\mathrm{m}=$ Quantity of parameters

On the basis of obtained average value can be drawn conclusions about compliance level of real image with positive. As a result of corporate image assessment can be developed a plan aimed at bringing the image parameters to the values corresponding to positive image.

\section{Assessment Method for Image of Higher Education Institutions (Ananchenkova P.I.).}

With the help of focus groups must be allocated, analyzed and tested basic image forming elements and suggested methodical basis for market research among students and university staff. Within research students compare image forming factors of university where they study ideal university where they would like to study, so that "ideal university" appears competitor to "real university." This assumption is quite justified, because in practice, for obvious reasons it is impossible to carry out market research in several competing universities, but such approach identified weaknesses in real image of university. Due to the fact that teachers and university employees are direct "translators" of university's image among students, it is important to find out how they rate the importance of various image forming factors.

The image forming factors in the focus-groups method are next: Level of comfort of the educational environment; fees of educational services; reliability of the university; quality of education; university style; foundation date of university; university's official symbols; students community; internal communications; rites and traditions; admission to the university; academic staff; facilities and equipment; study modes.

Each of these factors must be divided into qualifying details, which should be evaluated by the point system from 0 to 6 points. The results are at radar chart (Ananchenkova, 2009).

\section{Author's Assessment Method for Image of Regional Educational Institutions}

This method consists of combination of several qualitative techniques of image assessment. The following integrated indicators are calculated in the framework of the proposed method:

Integrated coefficient of university's image assessment considering regional features $\left(\mathrm{K}_{\mathrm{i}}\right)($ Feofanov, 2000):

$K_{i}=0.5 * I_{1}+0.3 * I_{2}+0.2 * I_{3}$

$I_{1}=$ Integrated score of university in monitoring of Ministry of education and science

$I_{2}=$ Integrated score of external university's image

$I_{3}=$ Integrated score of internal university's image

Integrated score of university in monitoring of Ministry of Education and Science $\left(I_{1}\right)$ (Vikhansky, 2016):

$I_{1}=\sum_{i=7} B_{i} * \frac{b_{i \text { fact }}^{M}}{b_{i \max }^{M}} * 10$

$i=$ Serial number of factor (from 1 to 7 )

$B_{i}=$ Weight of $\mathrm{i}$-factor, proportions

$b_{i \text { fact }}^{M}=$ Score of i-factor for university, points

$b_{i \max }^{M}=$ Maximum score of i-factor, points

Integrated score of external university's image $\left(\mathrm{I}_{2}\right)$ (Korolko, 2016):

$I_{2}=0.5 \sum_{j=13} B_{j}^{a} * b_{j}^{a}+0.5 \sum_{j=13} B_{j}^{e} * b_{j}^{e}$

$j \quad=$ Serial number of factor (from 1 to 13 )

$B_{j}^{a}=$ Weight of $\mathrm{j}$-factor for applicants, proportions

$b_{j}^{a}=$ Average score of $\mathbf{j}$-factor for applicants, points

$B_{j}^{e}=$ Weight of $\mathrm{j}$-factor for employer, proportions

$b_{j}^{e}=$ Average score of $\mathrm{j}$-factor for employer, points

Integrated score of internal university's image $\left(\mathrm{I}_{3}\right)$ (Echein, 2015): 


$$
I_{3}=0.5 \sum_{j=13} B_{j}^{s} * b_{j}^{s}+0.5 \sum_{j=13} B_{j}^{t} * b_{j}^{t}
$$

$\mathrm{j} \quad=$ Serial number of factor (from 1 to 13 )

$B_{j}^{s}=$ Weight of $\mathrm{j}$-factor for students, proportions

$b_{j}^{s}=$ Average score of $\mathrm{j}$-factor for students, points

$B_{j}^{t}=$ Weight of $\mathrm{j}$-factor for academics, proportions

$b_{j}^{t}=$ Average score of $\mathrm{j}$-factor for academics, points

\section{Author's Method of Research and Evaluation of Higher Education Institutions Image}

Research and analysis of methodology show that there is no common vision and unified system in evaluation of higher education institutions image: Some authors propose to evaluate the image as a cumulative picture that can be transferred by means of association, other authors estimate image according to its certain components.

For practical research and evaluation of higher education institutions image was developed the author's method.
Stage 1. Experts highlighting the most important characteristics affecting image (the most common responses of experts). Identified factors are the criteria for the current image assessment. These include:

- Fame among population

- $\quad$ Prestige and repute, ranking

- Convenient location

- High qualification of academics

- Various subject areas

- Alumni in labor market

- Foundation years

- Level of competitiveness of the university in Educational market

- Consumers reliance to the university

- Quality of education

- Reasonable tuition fees

- Positive image of the university students among city youth

- Personal approach

Stage 2. Market research among students, pupils, teachers, university administration and employers (business representatives). Key milestones of research are presented in Table 3.

Table 3: Key milestones of research and evaluation of university image

\begin{tabular}{ll}
\hline Milestone & Description \\
\hline Analysis of current education market & Economic and marketing analysis \\
Formulizing problem & Based on market analysis \\
Purpose and objectives of research & Based on problem \\
Research method and data & -Economics and Mathematics Methods of research (construction of simulation model), \\
collecting method & -Expert Method (experts' opinion), \\
& -Empiric Method (collection of information by means of sociological research or work \\
& with documents) \\
Sampling and segmentation & - Sampling (tabular and statistical method) \\
& - Segmentation of sample taking into account characteristic features of university's image: \\
& * Internal image (for students and academics) \\
& * External image (for applicants and employers) \\
Selection of measuring scales and & Measuring scales: \\
questionnaires composition & 1. Rated \\
& 2. Ordinal \\
& 3. Interval \\
& 4. Relative \\
& Parts of the questionnaire: An introduction, main, requisite. Identify criteria for assessment \\
& of university. \\
& - Questionnaire (students, applicants, stuff, employers) \\
Conducting research and & - Manual coding of responses \\
data processing & Statistical analysis: \\
& - Basic analysis, \\
& - Methods for estimating relationships between variables (contingency tables, variance, \\
Image assessment (Author's method) & discriminant, regression analysis), \\
Development of university's image & - Methods for identifying a data structure (factor and cluster analysis). \\
& Processing software: MS Excel, Statistica, SPSS Statistics, Maxima, Data Fit and others. \\
& Development of improvement program. \\
& Communicative effect, economic effect. \\
\hline
\end{tabular}


As part of marketing research sample groups have to rank image forming factors according to their importance and to evaluate characteristics of university in comparison to an ideal one. Factors need to be estimated from 1 to 10 using point system. The results are presented in the form of radar chart and tabular.

\section{Results of the Research}

Subjects of marketing in field of education are not just producers of educational services, but all market actors, such as consumers of educational servicesscholars, undergraduates, postgraduates.

Before adjustments of university's image, it is necessary to identify the current situation of issue, i.e., to conduct marketing research.

Image research and assessment of Vyatka State Agricultural Academy was conducted by our proposed method (Table 4).

This image assessment method will reveal most essential factors affecting image in eyes of responders and determine their importance (weight), Table 5. Also it is possible to compare Vyatka State Agricultural Academy's image to the" ideal university" and to identify the differences between the internal and external image.

Objective indicators of the analyzed university are lower than the normative values, except for indicators "Research activities" and "Salary and benefits for stuff" due to the tightening of legislation.

During the study was revealed the fact that stuff of university evaluates the image higher than external audiences (employers and applicants), Table 6. At the same time quite low scores on many criteria was received from the segment "Applicants". Employers appreciate the tuition quality of educational organization high.

According on proposed assessment method (formula 2) was received the result:

$$
K_{i}=0.5 * 11.436+0.3 * 8.030+0.2 * 7.226=9.491
$$

Thus the university's image on a 10-point scale rated high. As a result of frequency analysis and averages has been built a chart that reflects an assessment of the Vyatka State Agricultural Academy (Fig. 1).

Table 4: Key milestones of Vyatka state agricultural academy's image research

Milestone
$\begin{aligned} & \text { Marketing analysis of current state of } \\ & \text { educational services in Kirov city. }\end{aligned}$
educational services in Kirov city.

Formulizing problem

Purpose and objectives of research

Research method and data collecting method Sampling and segmentation

Selection of measuring scales and questionnaires composition Conducting research and data processing

Image assessment (Author's method)

Development of university's image Image improvement programme
Characteristics

21 educational institution,

7 main market participants ( 4 state universities, 1 private university, 1 branch of state university and 1 branch of private university),

The strongest participants in regional market are:

- Vyatka State University,

- Vyatka State Humanitarian University,

- Vyatka State Agricultural Academy.

Assess the current image of Vyatka State Agricultural Academy

The purpose is to find out image forming factors.

Objectives are to research image forming factors and evaluate their importance (weight). Research method is interview.

Data collecting method is questionnaire

- Sample - 119 people.

- Random sampling, divided into 4 groups:

- student (30 people);

- stuff (30 people);

- applicants (30 people);

- employers (29 people).

In drawing up the questionnaire used the following types of scales: Rated, ordinal, relative

Questionnaire conducting.

Data processing based on: Basic analysis (ranking characteristics) and analysis of variance. Software used for processing: SPSS Statistics.

9-8 points: Foundation years; convenient location; famous among population; high qualification of academics; quality of education.

-7 points: Reasonable tuition fees; positive image among youth; various subject areas; high level of competitiveness in educational market; consumers reliance to the university; alumni in labor market.

7-6 points: Prestige and repute, ranking; personal approach.

$K_{i}=9,491$

Development of improvement program.

Assessment of communicative and economic effect 
Table 5: Integrated score of university in monitoring of Ministry of Education and Science $\left(I_{I}\right)$ in 2014

\begin{tabular}{lllll}
\hline Criteria & Score of University & Maximum score & Weight, $\%$ & Score according on its weight \\
\hline Education & 53,950 & 60,000 & 20,000 & 0,180 \\
Research activities & 113,350 & 51,280 & 20,000 & 0,442 \\
International activities & 0,050 & 1,000 & 10,000 & 0,005 \\
Finance of University & 1029,160 & 1327,570 & 20,000 & 0,155 \\
Salary and benefits for stuff & 166,230 & 125,000 & 10,000 & 0,133 \\
Alumni employment & 85,000 & 80,000 & 15,000 & 0,159 \\
Others & 3,850 & 2,780 & 5,000 & 0,069 \\
Integrated score $\left(I_{l}\right)$ & & 11,436 & \\
\hline
\end{tabular}

Table 6: Integrated score of external $\left(I_{2}\right)$ and internal $\left(I_{3}\right)$ university's image

\begin{tabular}{|c|c|c|c|c|}
\hline \multirow[b]{2}{*}{ Criteria } & \multicolumn{2}{|c|}{ Internal image } & \multicolumn{2}{|c|}{ Exterlan image } \\
\hline & Students & Stuff & Applicants & Employers \\
\hline Quality of education & 8.670 & 7.900 & 7.570 & 8.000 \\
\hline High qualification of academics & 8.720 & 8.530 & 7.240 & 7.810 \\
\hline Alumni in labor market & 7.550 & 7.930 & 6.750 & 6.700 \\
\hline Foundation years & 9.070 & 9.600 & 7.340 & 9.430 \\
\hline Level of competitiveness of the university & 8.130 & 7.240 & 6.450 & 7.620 \\
\hline Consumers reliance to the university & 7.970 & 7.170 & 6.670 & 7.680 \\
\hline Various subject areas & 7.530 & 7.800 & 7.170 & 7.080 \\
\hline Positive image among city youth & 7.530 & 7.380 & 7.450 & 7.540 \\
\hline Prestige and repute, ranking & 7.530 & 6.930 & 6.300 & 7.180 \\
\hline Reasonable tuition fees & 7.830 & 8.520 & 6.860 & 6.700 \\
\hline Personal approach & 6.860 & 6.530 & 6.730 & 5.790 \\
\hline Fame among population & 8.930 & 8.930 & 7.130 & 8.970 \\
\hline Convenient location & 8.570 & 9.620 & 7.800 & 9.030 \\
\hline Average score & 8.171 & 7.889 & 6.996 & 7.457 \\
\hline Weight, \% & 0.500 & 0.500 & 0.500 & 0.500 \\
\hline Integrated score of external $\left(I_{2}\right)$ and internal $\left(I_{3}\right)$ image & 8.030 & & 7.226 & \\
\hline
\end{tabular}

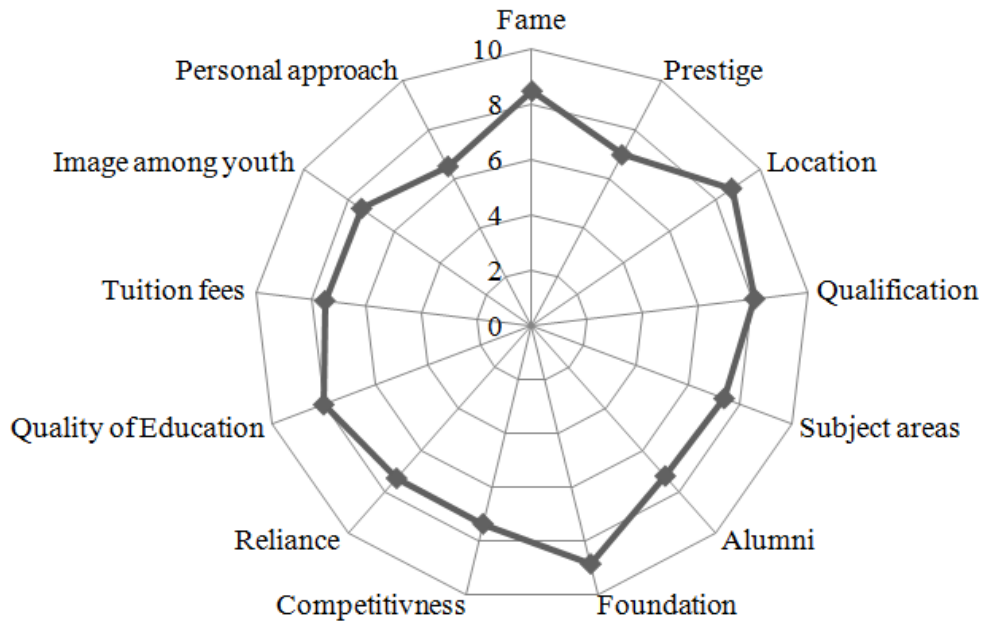

Fig. 1: Radar chart for Vyatka state agricultural academy

In result the current state of the Academy can be described as quite good and strong. Each criterion was assessed highly in comparison to an ideal characteristic of university. But at the same time there is no any criterion that would gain 10 points. This means that in strategic plan academy has directions for growth and perfection.
Using Analytics of Variance (ANOVA) has been found out the difference in ranking between categories of respondents:

- There is no dependence in categories "Prestige", "Subject Areas", "Alumni", "Quality of Education", "Image among youth", "Personal approach 
- In criterions of "Fame" and "Location" there is strong dependence between "Applicant" category and all others; it means that PR department should pay attention that potential applicants are not familiar with the Academy and its location

- The differences between categories in assessment of academic's qualification can be explained by the fact that neither applicants nor employers haven't had the experience of direct contact with academics and consequently the possibility to appreciate this experience. However the qualification of academics criterion has 2nd level of importance, so it is very important to pay attention to this difference and to pursue an active external policy

\section{Conclusion}

It should be noted that efforts in developing and promoting image of higher education services are undertaken in any educational institution, but often they have are fragmented or haphazard, about providing open days and participating in exhibitions.

It is not so much important for formation of higher education institution's positive image that we translate into the internal and external environment, as what they know, perceive and imagine about us. From this perspective, it is important to keep track of all communication flows coming from the university, as well as their impact to community.

Active implementation of marketing programs for image development will promote greater awareness of target groups, improve reputation and raise attractiveness. Proper delivery of information: Important information about the Academy, advantages and benefits, strengths and opportunities for applicants, students, teachers and employers, on activities of educational, research and entertainment, etc.

\section{Acknowledgement}

Authors thank Prof. Olga Fokina and Dr. Elena Ganebnykh for their support. Also thank the reviewers and editor for feedback that was used to improve this paper.

\section{Author's Contributions}

All authors equally made significant contribution to the research and design of this article.

Natalya Kataeva: Made literature review, coordinated the field survey, made data analysis and contributed to the writing of the manuscript.

Ekaterina Berezina: Made review of existing methodologies, designed the field survey, executed the field survey and contributed to the writing of the manuscript.

Alexey Sysolyatin: Executed the field survey and contributed to the writing of the manuscript.

\section{Ethics}

The random sample was utilized for the study. In this concern the results might have a slight error in calculation. However, the total number of respondents enable the reliability of the results.

\section{References}

Boulding, K.E., 1956. The Image: Knowledge in Life and Society. 5th Edn., University of Michigan Press, Ann Arbor, pp: 175.

Feofanov, O.A., 2000. Advertising: New technologies in Russia. 1st Edn., Saint-Petersburg, Peter, ISBN-10: 5-272-00037-4

Vikhansky, O.S., 2016. Strategic Management: Key Product Components.

Korolko, V.G., 2016. Basics of public relations.

Echein, S.L., 2015. Research in corporate image. Proceedings of the 8th Student's Scientific Conference, (SSC' 15), Kirov, Vyatka State University, pp: 354-358.

Semenov, A.K. and E.L. Maslova, 2009. Psychology and Ethics in Business and Management. 1st Edn., Dashkov and Co., Moscow, ISBN-13: 978-5-91131-614-613

Lukieva, E.B., 2009. Theory and practice of public relations (Part II). Tomsk Polytechnic University Press, Tomsk.

Arzhanova, K.A., 2015. Social-psychological mechanisms of forming image of political leader in election campaign. PhD Thesis, State University of Management.

Ozhegov, S.I., 1949. Dictionary of Russian Language. 1 st Edn., Onyx, Moscow, ISBN-13: 978-5-488-00919-6

Bogdanov, E. and V. Zazykin, 2004. Psychological Features of Public Relations. 1st Edn., SaintPetersburg, Peter, ISBN-10: 5-88782-382-8.

Tomilova, M.V., 2016. Model of corporate image.

Ananchenkova, P.I., 2009. Improvement of image as a competitiveness factor for high education institutions (organizational and methodological aspects). $\mathrm{PhD}$ Thesis, Academy of Labor and Social Relations.

Antipov, E.A. and E.B. Pokryshevskaya, 2010. Multicriterial model of image diagnostic. J. Market. Russia Abroad, 2: 54-59. 